\begin{tabular}{|c|l|}
\hline Title & Long-term outcomes after surgical and endovascular treatment of spinal dural arteriovenous fistulae \\
\hline Author(s) & Sasamori, Toru; Hida, Kazutoshi; Y ano, Shunsuke; A sano, Takeshi; Seki, Toshitaka; Houkin, Kiyohiro \\
\hline Citation & $\begin{array}{l}\text { European spine journal, 25(3), 748-754 } \\
\text { https://doi.org/40.1007/300586-015-3887-0 }\end{array}$ \\
\hline Issue Date & 2016-03 \\
\hline Doc URL & http://hdl.handle.net/2115/64636 \\
\hline Rights & The final publication is available at link.springer.com \\
\hline Type & article (author version) \\
\hline File Information & EurSpineJ25_748.pdf \\
\hline
\end{tabular}

Instructions for use 


\section{Long-term outcomes after surgical and endovascular treatment of spinal dural}

arteriovenous fistulae

Toru Sasamori ${ }^{1}$, Kazutoshi Hida ${ }^{2}$, Shunsuke Yano ${ }^{2}$, Takeshi Asano ${ }^{3}$, Toshitaka Seki ${ }^{1}$, Kiyohiro Houkin $^{1}$

${ }^{1}$ Department of Neurosurgery, Hokkaido University Graduate School of Medicine, Sapporo, Japan

${ }^{2}$ Sapporo Azabu Neurosurgical Hospital, Sapporo, Japan

${ }^{3}$ Department of Neurosurgery, Asahikawa Red Cross Hospital, Asahikawa, Japan

\section{Corresponding Author:}

Toru Sasamori, M.D.

Department of Neurosurgery, Hokkaido University Graduate School of Medicine

North-15 West-7, Kita-ku, Sapporo 060-8638, Japan

Tel: +81-11-706-5987, Fax: +81-11-708-7737

e-mail: mo_ri25@yahoo.co.jp 
Long-term outcomes after surgical and endovascular treatment of spinal dural arteriovenous fistulae 


\begin{abstract}
Purpose: To examine the validity of our treatment strategy for spinal dural arteriovenous fistulae (SDAVF), based on the treatment results and the long-term outcome.

Methods: This study included 50 SDAVF patients (38 men, 12 women, mean age 63.2 years) with progressive myelopathy. The treatment strategy involved embolization as the initial management tool and surgery if embolization was considered unsuitable. Their medical records were evaluated to identify the treatment results and functional outcomes. The mean follow-up period was 81.2 months (range 27 - 184 months).
\end{abstract}

Results: Complete obliteration was achieved in 22 (71.0\%) of 31 embolized patients and in 18 of 19 (94.7\%) operated patients. The initial success rate was significantly lower in embolized- than operated patients. At the last follow-up, 33 of the 50 patients (66\%) manifested improved gait and 16 (32\%) improved micturition. The activity of daily living (ADL) was improved in 33 (66\%). When we compared the rates of functional improvement at the last follow-up, there was no significant difference between patients treated initially by embolization or surgery.

Conclusions: The long-term outcomes in SDAVF patients treated by multidisciplinary management with first-line embolization were comparable to those in earlier surgical series. However, our results were unable to demonstrate the superiority of endovascular embolization to surgical treatment for SDAVF. For the purpose of justifying endovascular embolization as a first-line treatment for SDAVF, it will be necessary to show further improvement in both the initial treatment success and the complication rates.

(240 words)

Key words: spinal dural arteriovenous fistulae; embolization; multidisciplinary management; 
long-term outcome

\section{Introduction}

Spinal dural arteriovenous fistulae (SDAVF) are rare. In this disorder an abnormal arteriovenous shunt develops between the radiculo-meningeal artery and a radicular vein, typically within the dorsal surface of the dural root sleeve in the intervertebral foramen [1]. SDAVF, the most common vascular anomaly of the spine, develop most commonly in middle-aged men [2, 3]. Most SDAVF are located in the thoracolumbar region; cervical and sacral lesions are seen in $2 \%$ and $4 \%$ of patients, respectively [2]. Congestive myelopathy due to chronic venous hypertension is the most common pathological condition contributing to neurological deficits in patients with SDAVF [4].

The main goal of treatment for SDAVF is to disconnect the arteriovenous shunt on the venous side by endovascular embolization and/or surgical interruption [5-7]. As surgery is a safe and curative treatment with a low rate of recurrence, it is the gold standard for the management of SDAVF [8-10]. While embolization is less invasive, early reports demonstrated a high recurrence rate, especially when polyvinyl alcohol (PVA) was the embolizing agent [11, 12]. Advances in endovascular techniques and embolic materials improved the rate of successful embolization and good long-term outcomes have been reported [13-17].

The optimal management of SDAVF by initial surgery or embolization remains controversial and a multidisciplinary approach has been suggested [7, 16, 18-20]. It involves embolization as the initial management tool and surgery if embolization fails or is considered difficult and/or unsafe.

We have used the same strategy to address SDAVF for the past 16 years. Depending on the location and angiographic morphology of the SDAVF, endovascular embolization is our first choice 
because of its lower invasiveness. Endovascular embolization under local anesthesia is considered preferable in middle-aged and elderly patients who often have comorbidities such as hypertension, diabetes, and ischemic heart- and cerebrovascular disease. To validate our treatment strategy we assessed the clinical course and chronological functional outcome in patients with SDAVF subjected to a multidisciplinary approach where embolization is the first-line treatment.

\section{Materials and methods}

\section{Patient selection}

Between 1995 and 2011, 60 patients with SDAVF were treated at our hospital. All SDAVF were confirmed by spinal angiography and differentiated from vascular anomalies such as epidural arteriovenous fistulae (AVF), perimedullary AVF, and radicular arteriovenous malformations (AVM). We excluded 10 patients; 6 because they were referred for retreatment after unsuccessful treatment at other hospitals, 2 with subarachnoid hemorrhage, one asymptomatic patient, and one patient presenting with a spinal tumor. Consequently, the final study population was comprised of 50 SDAVF patients with myelopathy (38 males, 12 females, mean age $63.2 \pm 10.3$ years, range 39 - 82

years). All received their initial treatment at our hospital and were followed up for more than 2 years.

\section{Clinical characteristics}

The patterns of onset included sensory disturbance in the lower extremity ( $n=27,54 \%)$, lower extremity weakness $(n=11,22 \%)$, gait disturbance $(n=9,18 \%)$, back pain $(n=2,4 \%)$, and dysuria $(\mathrm{n}=1,2 \%)$. All 50 patients manifested gradual progression of the symptoms of myelopathy. The time 
from onset to diagnosis ranged from 1 - 96 months (mean $19.7 \pm 20.9$ months). The anomaly was initially misdiagnosed in 34 patients (68\%) as spinal intramedullary tumor, spinal degenerative disease, myelitis, and diabetic neuropathy; 6 of these patients were treated elsewhere by posterior lumbar decompression surgery and one patient had undergone steroid pulse therapy for myelitis.

At the time of diagnosis all patients presented with gait disturbance; 21 needed a wheelchair for locomotion. Weakness and sensory disturbance of the lower extremities were observed in 47 and 49 patients, respectively. Dysuria was noted in 44 patients including 19 who required urethral catheterization; 36 patients needed assistance in their daily life.

Spinal angiography revealed that 31 SDAVF were located at the thoracic-, 9 at the lumbar-, 3 at the sacral-, and 1 at the cervical level; 6 were at the craniovertebral junction (CVJ). Of the 50 lesions, 45 manifested a single feeder, the other 5 (3 CVJ-, 2 sacral lesions) were supplied by multiple feeders.

\section{Treatment strategy}

The treatment strategy in each case was developed after discussions between neurosurgeons and neurointerventionalists. Endovascular embolization was our first choice; surgery was considered if embolization appeared unsafe because the feeding artery arose from the same pedicle as the anterior or posterior spinal artery and when it was difficult to advance the microcatheter to the target feeder. We also judged embolization unsuitable for SDAVF located at the CVJ due to concerns about stray emboli migrating to vertebral arteries.

Embolization was performed under local anesthesia and systemic heparinization. After confirming that no spinal cord artery arose from the same pedicle as the feeding artery, N-butyl 
2-cyanoacrylate (NBCA) was carefully and slowly injected until the material reached the draining vein. The appropriate placement of the glue cast was evaluated on computed tomography (CT) images. When embolization failed to occlude the fistula with sufficient penetration of the glue into the draining vein we proceeded to surgery either immediately or after follow-up spinal angiography.

In patients undergoing surgery we performed 1- or 2-level hemilaminectomy to expose the fistula site at the intervertebral foramen. After opening the dura the intradural draining vein was coagulated and excised where it penetrated the inner layer of the dura. When possible, we also coagulated epidural feeding arteries. Intraoperatively we routinely monitored motor- and/or sensory evoked potentials.

The results of treatment were confirmed by spinal angiography during the same hospitalization. Postoperative magnetic resonance imaging (MRI) scans were acquired routinely approximately one week after treatment. We performed follow-up angiography and MRI after discharge if we suspected recurrent or residual SDAVF.

All clinical data were obtained by a retrospective chart review. Functional outcomes including gait, micturition, and activity of daily living (ADL) were evaluated at discharge, one year after treatment, and at the last follow-up session, using the modified Aminoff-Logue scale (ALS) (Table 1) and the modified Rankin scale (mRS) [1, 21]. The mean follow-up period was $81.2 \pm 38.3$ months (range 27 - 184 months). This study was approved by the institutional review board of our hospital.

\section{Statistical analysis}

All data were expressed as the mean \pm standard deviation. Data between 2 groups were compared 
with the Fisher's exact- or the Mann-Whitney $U$-test, as appropriate. The nonparametric Wilcoxon signed-rank test was used to compare the pre- and post-treatment ALS gait- and micturition scores and the pre- and post-treatment mRS scores. The level of significance was set at $\mathrm{p}<0.05$.

\section{Results}

Treatment results

Of the 50 patients, 31 underwent embolization. In 15 of the 19 operated patients, the specific considerations leading to surgery were CVJ lesions $(n=6)$, a feeding artery arising from the same pedicle as the anterior or posterior spinal artery $(\mathrm{n}=7)$, and difficulties with selective catheterization $(n=2)$. Thus, the surgical group comprised the more complex cases. Complete obliteration was achieved in 22 of 31 patients (71.0\%) by the initial embolization and in 18 of 19 patients (94.7\%) whose initial treatment was surgery. The initial success rate was significantly higher in operatedthan embolized patients ( $\mathrm{p}=0.035$, Fisher's exact test).

As shown in Table 2, 10 patients required retreatment; 6 who had undergone embolization 4 - 37 days earlier (mean $15.7 \pm 12.2$ days) were subsequently operated because of incomplete occlusion, 3 were operated due to recurrence 9 - 11 months (mean $9.7 \pm 1.2$ months) after embolization, and one underwent a second surgery due to the detection of residue 14 days after the initial operation.

We encountered complications in 4 of 31 patients (12.9\%) subjected to embolization. One patient treated early in this series by embolization with NBCA suffered a spinal cord infarct due to NBCA migration into the posterior spinal artery. His neurological deficits including position-sense and gait disturbance were transient, and he was able to ambulate without assistance at 103-month follow-up. Another patient presenting with asymptomatic aortic dissection was managed conservatively. In the 
other 2 patients we encountered extravascular dislocation of a guide wire during selective catheterization; neither suffered neurological deterioration and subsequent surgery improved or stabilized their neurological symptoms.

Of the 28 surgically treated patients, including 9 retreatment patients after embolization, 3 (10.7\%) developed complications. A patient with postoperative wound infection required surgical treatment after conservative management failed. The other 2 were reoperated 2 and 6 days after the first operation, respectively, to address an epidural or subdural hematoma. At the last follow-up all 3 of these patients manifested neurological improvement or stabilization.

Time course of neurological status after treatment

The chronological changes in the mean ALS gait and micturition- and the mean mRS scores are shown in Table 3. The mean duration of post-treatment hospitalization was $31.8 \pm 22.6$ days (range 5 - 120 days) and the mean follow-up period was $81.2 \pm 38.3$ months (range 27 - 184 months). For gait and ADL, the ALS- and the mRS scores significantly reduced during the follow-up period, compared with those before treatment (Wilcoxon signed-rank test, $\mathrm{p}<0.01$ ). For micturition, the ALS scores significantly reduced one year after treatment and at the last follow-up, compared with that before treatment (Wilcoxon signed-rank test, $\mathrm{p}<0.01$ ).

Of the 50 patients, 24 (48\%) were discharged home and 26 (52\%) were transferred to another institution for rehabilitation. At the time of discharge, the ALS scores for gait and micturition had improved in 30 (60\%) and 10 (20\%) patients, respectively (Fig. 1A and B), as had the mRS score for ADL in 25 (50\%) patients (Fig. 1C). Gait and ADL were improved in 36 (72\%) patients one year after treatment and in 33 (66\%) at the last follow-up; at that time, 14 (28\%) patients showed gait 
and ADL stabilization and 3 (6\%) manifested deterioration in both parameters (Fig. 1A and C). Improved micturition was recorded in 16 (32\%) patients one year after treatment and at the last follow-up; at that point, 30 (60\%) patients showed stabilization and in 4 (8\%) micturition had deteriorated (Fig. 1B).

When the patients with thoracolumbar lesions were divided into two groups based on the initial treatment, the baseline characteristics, including age, sex, time to diagnosis, and pretreatment functional scores were not significantly different between the two groups (Table 4). At the last follow-up, no significant differences were noted in the functional improvement rates between the two groups (Fig. 2).

\section{Discussion}

\section{Treatment results}

The present study showed that the initial success rate was significantly higher in operated- than embolized patients. This result is in line with data from earlier studies [10, 14, 16, 17]. Our surgical success rate of $94.7 \%$ was also comparable to previous studies $[9,10]$. In their meta-analysis of 16 surgical studies, Steinmetz et al. [10] found that complete obliteration was achieved in $98 \%$ of patients treated with surgery and Saladino et al. [9] reported complete surgical obliteration in 146 of 154 patients $(94.8 \%)$.

In our series, embolization was successful in 22 (71.0\%) of 31 patients. Like others [5, 22, 23], we defined success as occlusion of the fistula with sufficient penetration of the glue into the draining vein. Advances in endovascular techniques and improved embolic materials have raised the rate of successful embolization. Niimi et al. [15] reported that 39 of 47 (83\%) were successfully 
embolized with NBCA or isobutyl 2-cyanoacrylate (IBCA). Narvid et al. [14] treated 27 of 39 SDAVF patients (69.2\%) with single embolization using NBCA or PVA and Sherif et al. [16] reported that 17 of 19 patients (89.5\%) were successfully embolized with NBCA. More recently, Gemmete et al. [24] reported that 24 of 29 patients (82.8\%) were successfully embolized using Onyx or cyanoacrylate.

We encountered complications in 4 of 31 patients (12.9\%) treated by embolization, and in 3 of 28 operated patients (10.7\%). These complication rates were higher than those in the reported series. Niimi et al. [15] reported that 5 of 47 patients (10.6\%) subjected to embolization developed complications. Saladino et al. [9] reported complications in 5 of 154 operated patient (3.2\%). In their meta-analysis, Steinmetz et al. [10] found that the complication rate was lower after surgery than embolization (1.9 \% vs. 3.7\%).

\section{Functional outcomes}

Functional assessment at the last follow-up (mean follow-up period 81.2 months) showed that gait and micturition had improved in $66 \%$ and $32 \%$ of our patients, respectively. Our functional outcomes were comparable to other surgical studies [10, 16, 25]. Behrens and Thron [25] who assessed the long-term functional outcome a mean of 50 months after surgery found that $67 \%$ of their patients manifested improved motor activity. In their meta-analysis (mean follow-up period 35 months), Steinmetz et al. [10] found that overall outcome and micturition were improved in 55\% and 33\% of operated patients, respectively. Similarly, Sherif et al. [16] reported that gait and micturition were improved in $80.7 \%$ and $28.6 \%$ of patients, respectively, who had undergone multidisciplinary management with first-line embolization; their mean follow-up period was 103.4 
months. When they used the mRS to evaluate the general disability of SDAVF patients before and after treatment they reported that these scores had improved in $76.5 \%$; in our series the rate was $66 \%$.

Tacconi et al. [26] documented clinical improvement in $60 \%$ of surgically treated patients at 18 36 month follow-up. However, at final follow-up (mean follow-up period 147 months), only $10 \%$ of their patients manifested clinical improvement; in 65\% they observed deterioration. Neither we, nor others encountered similar findings. Our serial functional assessment showed a slight decrease in the rate of gait- and ADL improvements starting one year after treatment.

When we compared the rates of functional improvement in patients with thoracolumbar lesions at the last follow-up, there was no significant difference between patients treated initially by embolization or surgery (Fig. 2). Thus, although endovascular embolization risks a relatively higher rate of failure or recurrence than surgery, embolized patients achieved the same degree of functional improvement as did patients treated by surgery alone.

Endovascular embolization has a number of advantages, including the following: it can be performed under local anesthesia; it can be accomplished during the same session at which angiography was performed for diagnosis; and patients can expect to be ambulatory soon after treatment. These advantages come into play only if the treatment is reliable and safe. However, in the present study, the initial success rate of endovascular embolization was significantly lower than that of surgical treatment. Moreover, the complication rate with the endovascular embolization was comparatively high at $12.9 \%$, which was about the same as that $(10.7 \%)$ with surgical treatment. Thus, our present study results were unable to demonstrate the superiority of endovascular embolization to surgical treatment for SDAVF. 
For the purpose of justifying endovascular embolization as a first-line treatment for SDAVF, it will not be sufficient to merely show that the final outcome is comparable to that with surgical treatment; it will also be necessary to show further improvement in both the initial treatment success and the complication rates.

Our study has some limitations. The study population was relatively small. Because our study was retrospective, we performed statistical comparison between heterogeneous patient groups. The lack of uniformity in the location and angiographic morphology of SDAVF can affect the present results. Studies addressing these limitations are underway.

\section{Conclusions}

The long-term outcomes in patients with SDAVF treated by multidisciplinary management with first-line embolization were comparable to those in earlier surgical series. However, the initial success rate was significantly lower in embolized- than operated patients. Our results were unable to demonstrate the superiority of endovascular embolization to surgical treatment for SDAVF. For the purpose of justifying endovascular embolization as a first-line treatment for SDAVF, it will be necessary to show further improvement in both the initial treatment success and the complication rates.

\section{Acknowledgments}

The authors report no conflict of interest concerning the materials and methods used in this study or the findings specified in this paper. 


\section{References}

1. Aminoff MJ, Logue V (1974) The prognosis of patients with spinal vascular malformations. Brain 97:211-218

2. Jellema K, Tijssen CC, van Gijn J (2006) Spinal dural arteriovenous fistulas: a congestive myelopathy that initially mimics a peripheral nerve disorder. Brain 129:3150-3164. doi: 10.1093/brain/awl220

3. Oldfield EH, Doppman JL (1988) Spinal arteriovenous malformations. Clin Neurosurg 34:161-183

4. Hassler W, Thron A, Grote EH (1989) Hemodynamics of spinal dural arteriovenous fistulas. An intraoperative study. J Neurosurg 70:360-370. doi: 10.3171/jns.1989.70.3.0360

5. Jellema K, Sluzewski M, van Rooij WJ, Tijssen CC, Beute GN (2005) Embolization of spinal dural arteriovenous fistulas: importance of occlusion of the draining vein. J Neurosurg Spine 2:580-583. doi: 10.3171/spi.2005.2.5.0580

6. Krings T, Mull M, Gilsbach JM, Thron A (2005) Spinal vascular malformations. Eur Radiol 15:267-278. doi: 10.1007/s00330-004-2510-2

7. Van Dijk JM, TerBrugge KG, Willinsky RA, Farb RI, Wallace MC (2002) Multidisciplinary management of spinal dural arteriovenous fistulas: clinical presentation and long-term follow-up in 49 patients. Stroke 33:1578-1583

8. Huffmann BC, Gilsbach JM, Thron A (1995) Spinal dural arteriovenous fistulas: a plea for neurosurgical treatment. Acta Neurochir (Wien) 135:44-51

9. Saladino A, Atkinson JL, Rabinstein AA, Piepgras DG, Marsh WR, Krauss WE, Kaufmann TJ, Lanzino G (2010) Surgical treatment of spinal dural arteriovenous fistulae: a consecutive series of 
154 patients. Neurosurgery 67:1350-1357; discussion 1357-1358. doi: 10.1227/NEU.0b013e3181ef2821

10. Steinmetz MP, Chow MM, Krishnaney AA, Andrews-Hinders D, Benzel EC, Masaryk TJ, Mayberg MR, Rasmussen PA (2004) Outcome after the treatment of spinal dural arteriovenous fistulae: a contemporary single-institution series and meta-analysis. Neurosurgery 55:77-87; discussion 87-78

11. Morgan MK, Marsh WR (1989) Management of spinal dural arteriovenous malformations. J Neurosurg 70:832-836. doi: 10.3171/jns.1989.70.6.0832

12. Nichols DA, Rufenacht DA, Jack CR, Jr., Forbes GS (1992) Embolization of spinal dural arteriovenous fistula with polyvinyl alcohol particles: experience in 14 patients. AJNR Am J Neuroradiol 13:933-940

13. Andres RH, Barth A, Guzman R, Remonda L, El-Koussy M, Seiler RW, Widmer HR, Schroth G (2008) Endovascular and surgical treatment of spinal dural arteriovenous fistulas. Neuroradiology 50:869-876. doi: 10.1007/s00234-008-0425-3

14. Narvid J, Hetts SW, Larsen D, Neuhaus J, Singh TP, McSwain H, Lawton MT, Dowd CF, Higashida RT, Halbach VV (2008) Spinal dural arteriovenous fistulae: clinical features and long-term results. Neurosurgery 62:159-166; discussion 166-157. doi: 10.1227/01.neu.0000311073.71733.c4

15. Niimi Y, Berenstein A, Setton A, Neophytides A (1997) Embolization of spinal dural arteriovenous fistulae: results and follow-up. Neurosurgery 40:675-682; discussion 682-673

16. Sherif C, Gruber A, Bavinzski G, Standhardt H, Widhalm G, Gibson D, Richling B, Knosp E (2008) Long-term outcome of a multidisciplinary concept of spinal dural arteriovenous fistulae 
treatment. Neuroradiology 50:67-74. doi: 10.1007/s00234-007-0303-4

17. Song JK, Vinuela F, Gobin YP, Duckwiler GR, Murayama Y, Kureshi I, Frazee JG, Martin NA (2001) Surgical and endovascular treatment of spinal dural arteriovenous fistulas: long-term disability assessment and prognostic factors. J Neurosurg 94:199-204

18. Eskandar EN, Borges LF, Budzik RF, Jr., Putman CM, Ogilvy CS (2002) Spinal dural arteriovenous fistulas: experience with endovascular and surgical therapy. J Neurosurg 96:162-167. doi: 10.3171/jns.2002.96.1.0162

19. Ruiz-Juretschke F, Perez-Calvo JM, Castro E, Garcia-Leal R, Mateo-Sierra O, Fortea F, Iza B, Garbizu JM, Villoria F (2011) A single-center, long-term study of spinal dural arteriovenous fistulas with multidisciplinary treatment. J Clin Neurosci 18:1662-1666. doi: 10.1016/j.jocn.2011.03.008 20. Sivakumar W, Zada G, Yashar P, Giannotta SL, Teitelbaum G, Larsen DW (2009) Endovascular management of spinal dural arteriovenous fistulas. A review. Neurosurg Focus 26:E15. doi: 10.3171/2009.2.focus098

21. Bamford JM, Sandercock PA, Warlow CP, Slattery J (1989) Interobserver agreement for the assessment of handicap in stroke patients. Stroke 20:828

22. Krings T, Geibprasert S (2009) Spinal dural arteriovenous fistulas. AJNR Am J Neuroradiol 30:639-648. doi: 10.3174/ajnr.A1485

23. Rodesch G, Hurth M, Alvarez H, Tadie M, Lasjaunias P (2005) Spinal cord intradural arteriovenous fistulae: anatomic, clinical, and therapeutic considerations in a series of 32 consecutive patients seen between 1981 and 2000 with emphasis on endovascular therapy. Neurosurgery 57:973-983; discussion 973-983

24. Gemmete JJ, Chaudhary N, Elias AE, Toma AK, Pandey AS, Parker RA, Davagnanam I, Maher 
CO, Brew S, Robertson F (2013) Spinal dural arteriovenous fistulas: clinical experience with endovascular treatment as a primary therapy at 2 academic referral centers. AJNR Am J Neuroradiol 34:1974-1979. doi: 10.3174/ajnr.A3522

25. Behrens S, Thron A (1999) Long-term follow-up and outcome in patients treated for spinal dural arteriovenous fistula. J Neurol 246:181-185

26. Tacconi L, Lopez Izquierdo BC, Symon L (1997) Outcome and prognostic factors in the surgical treatment of spinal dural arteriovenous fistulas. A long-term study. $\mathrm{Br} \mathrm{J}$ Neurosurg 11:298-305

\section{Figure legends}

Fig. 1

Graphs demonstrating the chronological outcomes for gait (A), micturition (B), and ADL (C) after treatment. Outcomes were judged by the comparison with the pretreatment ALS- or mRS scores.

Fig. 2

Graphs showing the rates of functional improvement in patients with thoracolumbar lesions at the last follow-up. There was no significant difference between the initial embolization- and the initial surgery group. 
A

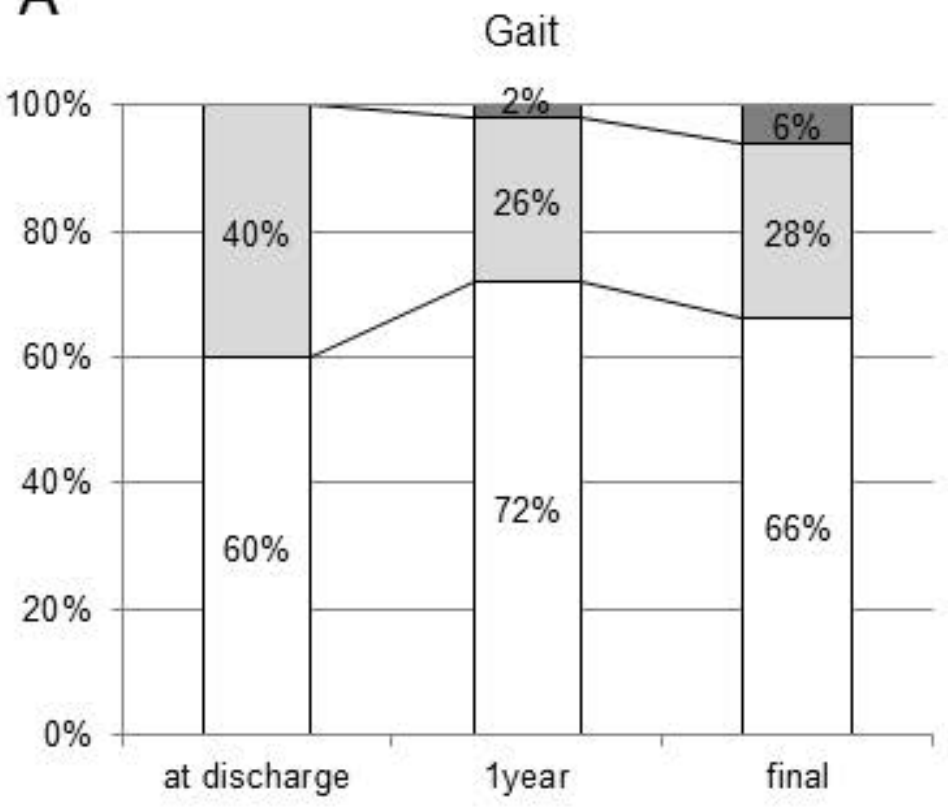

C

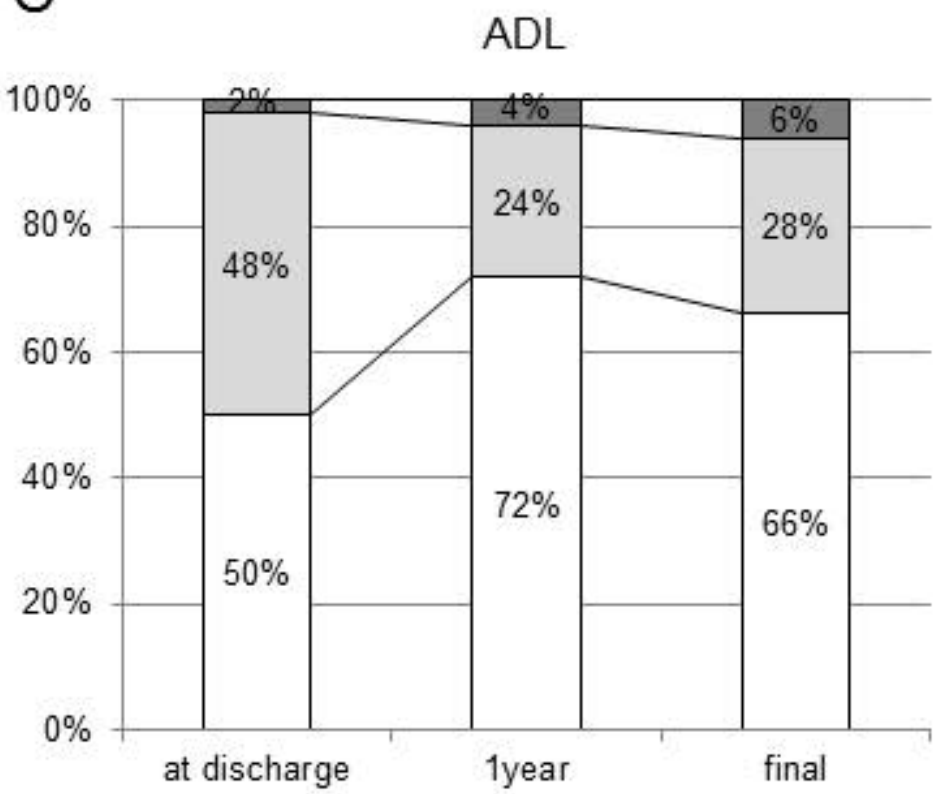

B

Micturition

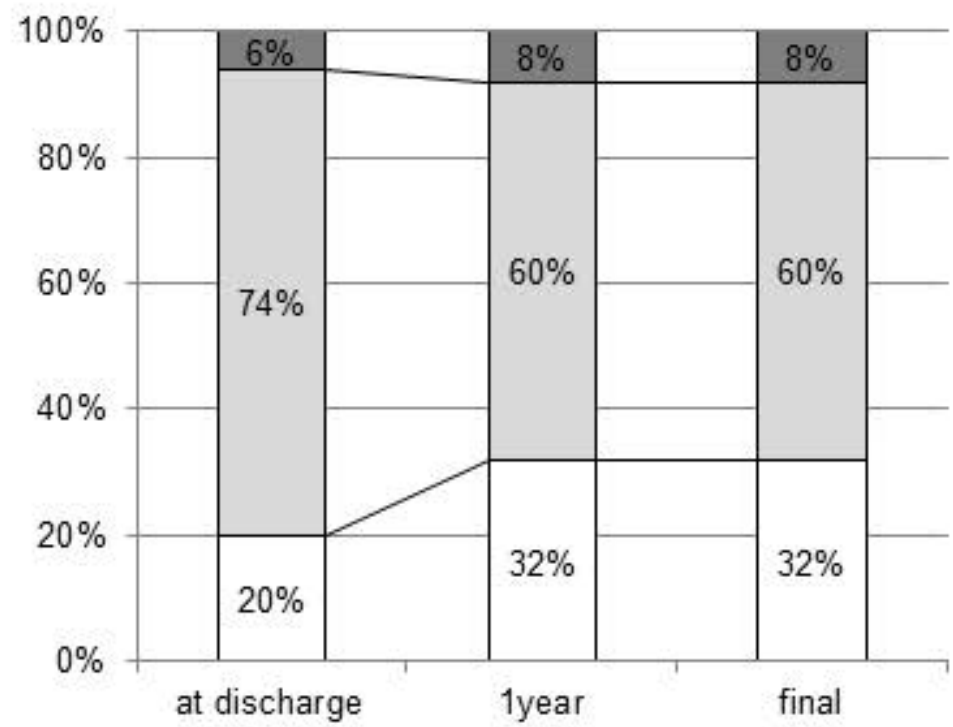

$\square$ deteriorated

口stabilized

口improved 


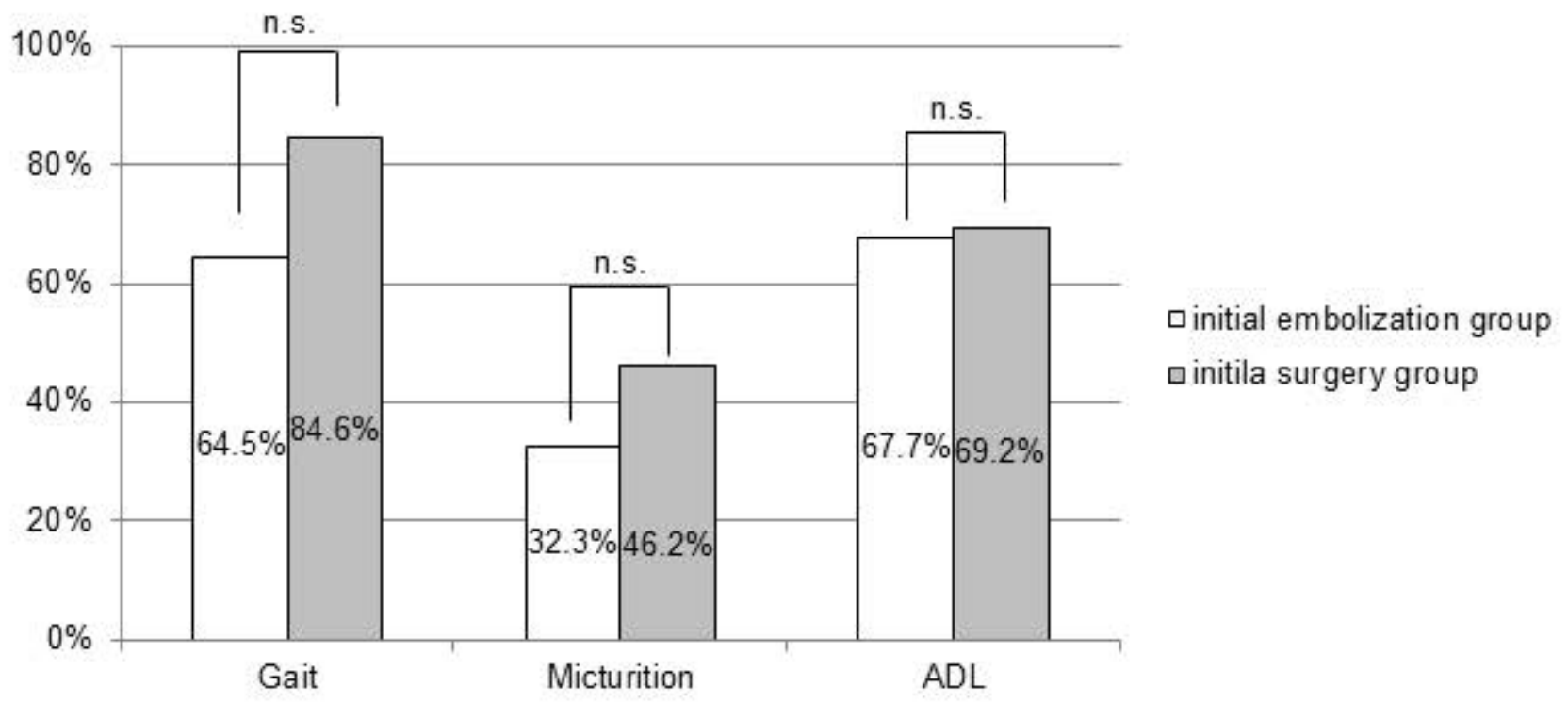

Fig. 2 
Table 1. Modified Aminoff-Logue scales for gait and micturition

\begin{aligned} & \hline Grade Definition \\ & \hline gait \\ & \hline 0 normal \\ & \hline 1 leg weakness, abnormal gait or stance, but no restriction of activity \\ & \hline 2 restricted activity \\ & \hline 3 requiring 1 stick for walking \\ & \hline 4 requiring 2 sticks, crutches, or walker \\ & \hline 5 confined to wheelchair \\ & \hline micturition \\ & \hline 0 normal \\ & \hline 1 hesitancy, frequency, urgency \\ & \hline 2 occasional urinary incontinence or retention \\ & \hline 3 total incontinence or persistent retention \\ & \hline\end{aligned}


Table 2. Clinical features of patients requiring retreatment.

\begin{tabular}{cccccc}
\hline Case & Age/Sex & Fistula level & Initial treatment & Retreatment due to & Time to retreatment \\
\hline 1 & 39/M & T5 & embolization & incomplete occlusion & 4 days \\
\hline 2 & $69 / \mathrm{M}$ & T7 & embolization & incomplete occlusion & 37 days \\
\hline 3 & $60 / \mathrm{F}$ & T7 & embolization & incomplete occlusion & 7 days \\
\hline 4 & $58 / \mathrm{M}$ & T8 & embolization & incomplete occlusion & 9 days \\
\hline 5 & $62 / \mathrm{M}$ & T8 & embolization & incomplete occlusion & 21 days \\
\hline 6 & $68 / \mathrm{F}$ & T11 & embolization & incomplete occlusion & 16 days \\
\hline 7 & 80/M & T11 & embolization & recurrence & 9 mos \\
\hline 8 & $60 / \mathrm{M}$ & T12 & embolization & recurrence & 9 mos \\
\hline 9 & $54 / \mathrm{M}$ & T5 & embolization & recurrence & 11 mos \\
\hline 10 & $69 / \mathrm{M}$ & CVJ & surgery & residue & 14 days \\
\hline
\end{tabular}

M; male, F; female, T; thoracic, CVJ; craniovertebral junction 
Table 3. Chronological changes in the ALS gait and micturition- and the mRS scores.

\begin{tabular}{lllll}
\hline & pretreatment & at discharge & 1 year & final \\
\hline ALS gait score & $3.64 \pm 1.38$ & $2.90 \pm 1.28^{* *}$ & $2.52 \pm 1.31^{* *}$ & $2.60 \pm 1.36^{* *}$ \\
\hline ALS micturition score & $1.96 \pm 1.03$ & $1.78 \pm 0.97$ & $1.58 \pm 1.05^{* *}$ & $1.60 \pm 1.03^{* *}$ \\
\hline mRS score & $3.42 \pm 1.21$ & $2.92 \pm 1.28^{* *}$ & $2.56 \pm 1.16^{* *}$ & $2.62 \pm 1.09^{* *}$ \\
\hline
\end{tabular}

ALS; Aminoff-Logue scale, mRS; modified Rankin scale

All values are the mean \pm standard deviation. ${ }^{* *} \mathrm{p}<0.01$ compared with the scores recorded at the time of diagnosis. 
Table 4. Baseline characteristics of the patients with thoracolumbar lesions based on their initial treatment.

\begin{tabular}{llll}
\hline & \multicolumn{2}{c}{ Initial treatment } \\
\cline { 2 - 3 } & embolization & surgery & P value \\
\hline no & 31 & 13 & \\
\hline age, yrs & $63.3 \pm 10.8$ & $62.4 \pm 8.0$ & 0.60 \\
\hline male sex & 23 & 11 & 0.70 \\
\hline time to diagnosis, mos & $18.8 \pm 18.2$ & $23.7 \pm 29.1$ & 0.88 \\
\hline Baseline scores & & & \\
\hline ALS (gait) & $3.74 \pm 1.32$ & $3.15 \pm 1.41$ & 0.18 \\
\hline ALS (micturition) & $2.00 \pm 0.97$ & $1.79 \pm 1.09$ & 0.52 \\
\hline mRS & $3.55 \pm 1.18$ & $3.00 \pm 1.15$ & 0.15 \\
\hline
\end{tabular}

ALS; Aminoff-Logue scale, mRS; modified Rankin scale 